\author{
Kelly Bessa \\ Geógrafa, Professora Doutora dos Cursos de Geografia e do Programa de \\ Pós-Graduação em Geografia da Universidade Federal do Tocantins (UFT) \\ kellybessa@uft.edu.br
}

\title{
Estudos sobre a rede urbana: os precursores da teoria das localidades centrais
}

\begin{abstract}
Resumo
Dentre os estudos sobre redes urbanas, destacam-se aqueles que dizem respeito à hierarquia de seus centros. Uma das bases teóricas mais ricas e conhecidas é a "teoria das localidades centrais", formulada por Walter Christaller e publicada em 1933. Nesse contexto, o presente trabalho tem por finalidade apresentar as contribuições dos estudos sobre a hierarquia dos centros urbanos que antecederam a obra clássica do citado autor. Ressalta-se que tais estudos foram, posteriormente, aprofundados por Christaller, por meio de extensa compilação bibliográfica, que resultou na plena sistematização da temática da organização espacial dos centros urbanos, ainda nos anos de 1930, segundo sua hierarquia.
\end{abstract}

Palavras-chave: Rede urbana, Hierarquia dos centros urbanos, Teoria das localidades centrais.

\begin{abstract}
STUDY CONCERNING URBAN NETWORK: PIONEERS OF THE THEORY OF CENTRAL PLACE

Within studies concerning urban networks those that refer to hierarchies of their centers stand out most. One of the richest and best known bases is the "theory of central place" formulated by Walter Christaller and published in 1933. In this context this study aims at presenting contributions to the study of hierarchies in urban centers which antecede the classic above mentioned study. It is noteworthy that these studies were, later, more profoundly examines by Christaller through
\end{abstract}


a extensive bibliographic collection, which resulted in full systemization of the theme of space organization of urban centers, already in the 1930s, according to his hierarchy.

Key-words: Urban network, Hierarchy of urban centers, Theory of central place.

\section{Introdução}

Recentemente, em função da complexidade do longo processo de urbanização e, também, do próprio processo de globalização, vêm ocorrendo profundas reestruturações na rede urbana, conceituada, segundo Corrêa (2006, p. 7), como o "conjunto funcionalmente articulado de centros urbanos e suas hinterlândias [...]". Como sugere Sposito (2011, p. 126), no período atual, há que se reconhecer uma notória "[...] reestruturação das relações entre as cidades", e ainda entre as próprias redes urbanas, como resultado da redefinição dos papéis exercidos pelos distintos centros e pelos, igualmente, distintos segmentos de redes urbanas. Nesse contexto de reestruturação, nota-se profunda discussão a respeito da natureza hierárquica dessas relações, seja entre os centros, seja entre as redes urbanas, apontando para a necessidade de desvendamento dos conteúdos e sentidos dessas transformações.

Os estudos sobre hierarquia dos centros na rede urbana têm-se constituído em uma importante tradição no âmbito da Geografia. Dentre os estudos, destaca-se, como base teórica, a "teoria das localidades centrais", formulada pelo geógrafo alemão Walter Christaller, cujo original foi publicado em 1933 e traduzido para o inglês em 1966 (CHRISTALLER, 1966).

No entanto, estudos acerca da interação entre os centros urbanos e da natureza hierárquica dessas relações já haviam sido realizados, anteriormente a Christaller (1966), pois o interesse pela hierarquia dos centros urbanos remonta ao século XVIII, quando se ampliou, sobremaneira, a interdependência e a diferenciação entre esses. A articulação crescente entre cidades e lugares, tanto no período que a precedeu, como após a Revolução Industrial, é reflexo e, ao mesmo tempo, é condição para as mudanças estruturais desse momento. Essas mudanças consubstanciaram a constituição efetiva de redes urbanas hierarquizadas, amparadas numa 
divisão social, técnica e territorial do trabalho que se ampliava, pois tais redes organizaram-se de modo que parte dos centros urbanos encontrava-se subordinada a outros centros, quer dizer, a interdependência entre os centros urbanos passou a ocorrer por meio da crescente subordinação de uma cidade a outra, num sistemático processo de hierarquização.

De fato, os centros urbanos passaram a desempenhar papéis crescentemente diferenciados, com base nas "funções centrais" e na magnitude de suas relações econômicas e políticas, bem como na condição, maior ou menor, como centro de decisão e de comando do próprio processo em curso, como resultado da ação de capitalistas, industriais e instituições políticas. Essas ações implicaram o estabelecimento de interações espaciais assimétricas também entre as cidades, e não apenas entre estas e o campo, de modo a constituir uma divisão territorial do trabalho em escala interurbana.

Essa interdependência de natureza hierárquica entre centros urbanos, a partir desse momento, passou a merecer atenção por parte de geógrafos e também de não-geógrafos, sendo assim, foram produzidos estudos que antecederam a tese clássica de Walter Christaller, marco de referência para os estudos sobre redes urbanas. Dentre os principais precursores, estão Richard Cantillon, Jeann Louis Reynaud e León Lalanne, que colocaram em evidencia a natureza hierárquica da relação entre os centros urbanos e propuseram uma formulação de hierarquia urbana semelhante à de Christaller (1966). Dentre outros antecessores estão também um grupo de sociólogos rurais estadunidenses, no qual sobressaem os estudos de Charles J. Galpin e J. H. Kolb; e um grupo de planejadores urbanos ingleses, com destaque para Charles B. Fawcett. Esses são trabalhos de não-geógrafos, que, via de regra, tinham um sentido prático-administrativo em um momento de transformação da rede urbana, por isto a discussão sobre a "área de mercado" ou, na concepção de Christaller (1966), sobre o "alcance espacial" (range e threshold) dos centros urbanos, quando ocorre um esforço de geografização da análise. O interesse dos geógrafos pela temática da hierarquia urbana foi despertado, sobretudo, a partir das décadas de 1920 e 1930, a exemplo dos estudos de Robert Dickinson, Hans Bobek, Vaino Auer e do próprio Christaller (1966). 
Nessa perspectiva, o presente trabalho tem por finalidade apresentar as contribuições dos estudos relativos à temática da hierarquia dos centros urbanos que antecederam à tese de Christaller (1966), apontando o que foi produzido e os contextos que nortearam a produção desses estudos. Tal temática foi, em seguida, aprofundada por Christaller (1966), por meio de extensa compilação bibliográfica, que resultou na plena sistematização da organização espacial dos lugares centrais no sul da Alemanha, ainda nos anos de 1930.

A teoria das localidades centrais, por fim, representa "[...] um quadro teórico sobre a diferenciação dos núcleos urbanos de povoamento $[\ldots]$ ". Tal diferenciação revela-se por meio de "[...] uma nítida hierarquia definida simultaneamente pelo conjunto de bens e serviços oferecidos pelos estabelecimentos do setor terciário e pela atuação espacial dos mesmos". Essa hierarquia, por sua vez, "[...] caracteriza-se pela existência de níveis estratificados de localidades centrais, nos quais os centros de um mesmo nível hierárquico oferecem um conjunto semelhante de bens e serviços e atuam sobre áreas semelhantes no que diz respeito à dimensão territorial e ao volume de população", como aponta Corrêa (1988, p. 61). Nesse sentido, os centros urbanos capazes de exercer "centralidade" são denominados "lugares centrais". Enquanto que a "centralidade" de que dispõem é proveniente de seus papéis como centros distribuidores de bens e serviços, quer dizer, é resultante das "funções centrais" que tais centros são capazes de desempenhar em sua hinterlândia ou área de influência (CHRISTALLER, 1966), gerando, consequentemente, uma diferenciação de caráter hierárquico, determinada a partir do alcance espacial.

Na gênese desse processo de diferenciação e de hierarquização dos centros urbanos, atuam, portanto, os mecanismos de "alcance espacial máximo" (maximum range) e "alcance espacial mínimo" (minimum range). Ressalta-se que da combinação desses recortes espaciais define-se a "área de influência" ou "área de mercado" de um determinado centro, por meio de uma hierarquização entre as localidades centrais (CHRISTALLER, 1966).

Desse modo, Christaller (1966) desenvolveu a tese de que os centros urbanos, em decorrência dos mecanismos de alcance espacial máximo e mínimo, das vantagens locacionais e das economias de aglomeração, 
passam a apresentar uma diferenciação de caráter hierárquico, na qual os centros de nível hierárquico mais elevado são dotados de uma área de influência mais ampla, onde estariam contidos os centros com níveis hierárquicos inferiores e, portanto, subordinados pelos primeiros centros, de modo a configurar uma rede hierárquica. Cumpre salientar que esse processo de diferenciação foi acentuado com o avanço do capitalismo, sobretudo, a partir do século XVIII, estando, desse modo, associado a uma fase desse sistema.

Nos dias atuais, contudo, com o avanço da globalização econômica e do próprio processo de urbanização da sociedade, notam-se novas transformações na configuração das redes urbanas, incluindo-se a natureza hierárquica das relações. Pesquisadores dessa temática vêm alertando para a redefinição e a complexificação dos papéis dos centros urbanos e, por conseguinte, da própria rede, sugerindo, até mesmo, a existência de "redes de redes" e de "sistemas urbanos", nos quais haveria um novo caráter na interação entre os centros urbanos e entre suas respectivas redes.

Santos (1994), tomando como referência a realidade brasileira, alerta que o esquema tradicional e piramidal da relação entre os centros, em uma rede urbana, fora rompido ainda na década de 1970, quando uma nova hierarquia urbana se configurou como resposta às "novas redes de relações" impostas, levando a um "[...] desmantelamento da rede urbana em sua concepção tradicional" (SANTOS, 1979, p. 262). Veltz (2002), de modo semelhante, porém adotando a França como referência, destaca que, a partir do final do século XX, não se pode mais explicar a relação entre os centros urbanos pelo "paradigma hierárquico", também percebido como piramidal. Corrêa (2006), indicando a diversidade de redes urbanas existentes, alerta para a necessidade de se discutir as estruturas desse tipo particular de rede geográfica, bem como a natureza da complexa diferenciação entre elas, com base em observações empíricas sobre o fato no território brasileiro. Sposito (2011, p.130), por sua vez, chama atenção para a redefinição do "[...] escopo das redes urbanas [...]", que se tornam mais complexas, porém, "[...] não estritamente hierárquicas", primordialmente, pela "[...] conformação de novas redes estruturadas por relações horizontais, entre centros urbanos complementares, similares ou não". 
Nesse contexto, visando a contribuir com o debate, o presente artigo trata dos estudos pioneiros acerca da hierarquia dos centros urbanos. A aproximação de tais estudos com o debate atual possibilita um mergulho na verificação e na reflexão sobre a natureza da rede urbana, segundo um ângulo específico que é o da hierarquia, que baliza a articulação entre os centros e entre as redes urbanas, expressando diferenciações quantitativas e qualitativas.

\section{Os precursores da teoria das localidades centrais}

A constituição de uma efetiva rede de centros de distribuição de bens e serviços hierarquizados, mesmo que em condições embrionárias, deu-se a partir do século XVI, com a expansão do capitalismo na Europa. De acordo com Corrêa (2001, p. 17), "a emergência de uma rede hierarquizada e integrada [...] de centros de distribuição varejista e de serviços, isto é, de localidades centrais, se verifica com o capitalismo, com o domínio de um modo de produção onde o capital penetra na esfera da produção." Ressalta-se, contudo, que tal processo não se iniciou com o capitalismo, pois existiram redes urbanas antes do feudalismo, a exemplo da rede de cidades sob domínio do Império Romano, na Antiguidade.

A emergência de novas estruturas econômicas e também políticas foi marcada por novas configurações espaciais, especialmente com relação a uma progressiva divisão social e territorial do trabalho, que implicou a articulação entre os lugares - fosse um centro urbano, uma região, um país. Essa articulação, entretanto, ocorreu de modo espacialmente desigual, sustentada no poder centralizado do Estado Moderno, resultando em processos de diferenciação e de hierarquização.

No que tange à rede urbana, o capitalismo recriou as condições de sua existência, como acontecera com a formação do Império Romano, visto que, além de pontos fixos, os centros urbanos, no território, exige-se, para a efetiva constituição de uma rede urbana, a existência de uma economia de mercado e de um mínimo de articulação entre esses referidos pontos. Dessa forma, a cidade torna-se o lugar da divisão social e territorial do 
trabalho. Neste último caso, os centros urbanos passam a ser os elos de ligação na totalidade do espaço, seja em nível regional, nacional ou mesmo internacional.

Com o avanço do capitalismo, a atividade comercial ganhou, gradativamente, um novo significado, ampliando o território de atuação e estabelecendo, entre a dimensão da produção e do consumo, a circulação (distribuição e troca de mercadorias produzidas), cujo caráter, na obtenção do lucro, passou a desempenhar papel fundamental na sociedade e na organização espacial. Nota-se, contudo, que a problemática tanto da localização como da circulação só aparece como uma questão crucial, aos olhos da classe dominante e do Estado, com o capitalismo. As articulações, provenientes da circulação de mercadorias, estão no cerne dos processos de diferenciação e de hierarquização entre os centros urbanos, pois, em uma economia de mercado, a oferta e o consumo de mercadorias e serviços realizam-se de forma desigual e estratificada, gerando, por conseguinte, uma hierarquia entre os pontos. Isso define uma maior diferenciação entre os núcleos urbanos, o que inclui, também, um maior aprofundamento do processo de hierarquização. Nesse contexto, a localização das atividades e da população assume uma importância crucial, tanto para os capitalistas quanto para o Estado. Dessa importância, emerge, mesmo que implicitamente, o interesse em compreender a natureza e o significado da rede urbana.

Mesmo em tempos remotos, a organização espacial da circulação, fundamentada na crescente divisão social e territorial do trabalho, tinha os centros urbanos como locais que se interligavam por meio do comércio e da prestação de serviços, implicando uma configuração espacial particular, na qual os centros ganharam novos e distintos conteúdos, diferenciando-se, tendo em vista as especializações produtivas e a consequente complementaridade entre as áreas especializadas, gerando, portanto, interações espaciais díspares.

O processo de diferenciação e de hierarquização dos centros urbanos foi, primeiramente, percebido pelo francês Richard Cantillon, ainda no século XVIII, em um contexto pré-industrial (PONSARD, 1958; CORRÊA, 1986). Nesse contexto, o capitalismo mercantil, apoiado no fim dos mono- 
pólios feudais sobre a produção do campo e dos monopólios corporativos sobre a produção artesanal e manufatureira, promoveu, via comerciantes e banqueiros, a ampliação dos territórios de atuação do capital comercial, transformando os centros urbanos em locais de acumulação da riqueza gerada nessa fase do capitalismo.

Cantillon, que era banqueiro, foi pioneiro na tentativa de elaboração de uma teoria a respeito da hierarquização urbana, visto que seu esquema, publicado em 1755, consistia em uma das primeiras experiências de esquematização dos processos de diferenciação entre os centros urbanos em termos de hierarquia em território francês. De fato, como sugere Corrêa (1986), Cantillon elaborou um esboço da "teoria das localidades centrais" cerca de 180 anos antes de Christaller (1966).

O interesse de Cantillon pela organização espacial dos centros urbanos foi despertado em razão da necessidade de uma racionalização de "tempo" e de "espaço" em seus negócios bancários, ou seja, foi a necessidade de racionalização no campo monetário que despertou o interesse de Cantillon para o entendimento da articulação entre os centros urbanos, visto que suas preocupações estavam centradas em questões referentes ao "mundo dos negócios".

No entanto, há que se reconhecer que as contribuições de Cantillon com relação à "análise econômica do espaço", considerando a organização espacial das atividades econômicas, especialmente do comércio e da circulação de capital, estão situadas no cerne da discussão do enfoque locacional, que, com a emergência do capitalismo, ganhou importância fundamental (PONSARD, 1958).

Assim, buscando maximizar a circulação de capital por meio de uma possível economia de "tempo" e de "espaço", Cantillon demonstrou um esquema de diferenciação entre os centros urbanos, no qual estabeleceu, inclusive, níveis hierárquicos distintos. Isto é, Cantillon percebeu que a diferenciação entre os centros urbanos era de natureza hierárquica, base fundamental do esquema da rede de localidades centrais de Christaller (1966). Na concepção desse esquema, Cantillon analisou a sociedade por meio de duas dimensões interdependentes, sendo uma "vertical", oriunda de "circuitos de capital", criadas, sobretudo, a partir dos pagamentos 
bancários, quer dizer, em razão da circulação de capital; e outra "horizontal", proveniente de "circuitos" envolvendo as relações cidade-campo (PONSARD, 1958). A noção de "Circuitos" remete à ideia de movimento em um determinado espaço, o que denota que Cantillon considerou, em suas análises, um conjunto de centros de uma dada região e também o papel desempenhado por esse conjunto na economia e no estabelecimento de interações, principalmente nas relações interurbanas e entre a cidade e o campo.

Assim, a partir de relações "verticais" e "horizontais", Cantillon admitiu um esquema de diferenciação entre os centros urbanos de natureza hierárquica, definido pelas economias de transporte, pela densidade da população, pela drenagem da renda fundiária e pela presença do poder político. O esquema proposto estabeleceu a existência de quatro níveis hierárquicos, com a seguinte tipologia: aldeias, pequenas cidades, grandes cidades e capitais (PONSARD, 1958).

Para Cantillon, o aparecimento de aldeias decorre da necessidade de "economias de tempo" e "economias de transporte", que forçam a população a permanecer junto às terras que cultiva e também determinam o consequente surgimento de novas aldeias quando as "economias de transporte" forem afetadas por grandes deslocamentos, implicando maior gasto de tempo (PONSARD, 1958). No caso das aldeias, a área de influência era espacialmente restrita em função do número de habitantes necessários ao trabalho no campo e também em razão da natureza das culturas cultivadas. Cantilon notou que algumas dessas aldeias foram, progressivamente, transformadas em "burgos", ou seja, passaram a desempenhar papéis de mercado por meio de "economias de transporte". O raio desses mercados definia a extensão da área de influência dessas aglomerações, cuja dimensão era dada pela densidade da população (PONSARD, 1958).

As pequenas cidades eram, na verdade, espaços com certo grau de centralidade, uma vez que dispunham de uma área de mercado a partir da qual seriam capazes de abastecer uma população exterior, bem como de controlar a renda fundiária proveniente das aldeias.

A aglomeração de grandes proprietários fundiários deu origem às grandes cidades. Esses proprietários perceberam que a concentração de 
seus negócios e da produção de suas terras em um grande centro seria capaz de proporcionar uma redução nos custos com transporte e com impostos (PONSARD, 1958). As grandes cidades possuíam áreas de influência maiores, incluindo as pequenas cidades e suas respectivas áreas de influência, assim como tinham o controle da renda fundiária de grandes, médios e pequenos proprietários rurais. A concentração simultânea de grandes proprietários fundiários e do poder político deu origem às capitais. A capital era capaz de desempenhar múltiplos papéis, dentre os quais as funções de administração pública, visto que era sede do poder político (PONSARD, 1958). Destarte, possuía alcance espacial e mercados mais amplos, o que incluía o atendimento de uma população residente em toda uma região ou país e, também, a capacidade de maior controle da renda fundiária.

Cantillon estruturou um esquema hierárquico com padrões sistemáticos, tanto no que se refere às funções exercidas pelos núcleos, quanto no que tange às regiões de influência, pois o acúmulo das funções foi percebido em cada um dos níveis hierárquicos, sendo que a capital, centro de nível hierárquico mais elevado, abarcava ampla região de influência, na qual estavam contidas as áreas de influência das grandes cidades, das pequenas cidades e das aldeias.

Como demonstrado, Cantillon foi capaz de perceber a existência de processos de diferenciação de natureza hierárquica entre os centros urbanos a partir da circulação de capital. Nas palavras de Corrêa (1989, p.20), Cantillon, "[...] tentando racionalizar em termos de tempo e espaço seus negócios bancários, ressalta a natureza hierárquica das cidades". O referido autor foi também capaz de identificar categorias no intento de explicar a relação entre os centros urbanos, dentre elas: custos de transporte, densidade demográfica e área de mercado, que, nesse período, eram eminentemente locais ou regionais.

No final do século XVIII, a Revolução Industrial conferiu ao capitalismo um estágio mais avançado, implicando um aprofundamento da divisão social e territorial do trabalho. Nesse contexto, a dinâmica capitalista afetou de forma acentuada a rede urbana, pois à medida que se expandia a economia de mercado, com a interligação de um número crescente de 
áreas e com a expansão desigual da oferta de bens e serviços, ampliava-se o processo de diferenciação entre os centros urbanos, implicando o aprofundamento do processo de hierarquização.

Nesse contexto, o também francês Jean Louis Reynaud, um engenheiro de minas, cujos interesses sociais e acadêmicos levaram à co-organização de uma enciclopédia e à criação de uma Escola de Administração, demonstrou especial interesse pelas questões espaciais, estando convencido da necessidade de intervenção do Estado para garantir uma organização "racional" da sociedade no espaço. Com relação aos estudos urbanos, cumpre registrar que a contribuição de Reynaud estende-se de estudos acerca da organização interna das cidades a estudos sobre a rede urbana (ROBIC, 1982; CORRÊA, 1986; PUMAIN, 1994; PUMAIN, 2004).

No que tange à organização espacial dos centros urbanos, Reynaud elaborou, por volta do ano de 1841, um "sistema geral de cidades", no qual propôs uma estrutura hierárquica de centros urbanos com três ou quatro níveis funcionais, que, com suas "áreas de influência", constituíam um conjunto de "hexágonos embutidos" (ROBIC, 1982; CORRÊA, 1986, PUMAIN, 1994; PUMAIN, 2004). Tal concepção foi, posteriormente, utilizada por Christaller (1966), que conferiu padrões de redes hexagonais à organização espacial dos diferentes níveis de "localidades centrais" e de suas áreas de influência.

A base de análise do sistema de centros urbanos de Reynaud foi a distribuição da população agrícola, naquilo que considerou "sistema geográfico de agregações agrícolas". Tal sistema está fundamentado em três princípios interdependentes - sociabilidade, fator econômico e administração (ROBIC, 1982; CORRÊA, 1986). O princípio da "sociabilidade" é dado por uma força centrípeta, cuja tendência é agregar a população agrícola, promovendo a formação de "aldeias agrícolas" capazes de reunir certo número de pessoas, cujo limite é determinado por custos de transporte, pois, além de certa distância, os agricultores são obrigados a construir outras aldeias, para, assim, equacionar o problema da elevação dos custos com transporte (ROBIC, 1982; CORRÊA, 1986). O "fator econômico", de um lado, opõe-se ao princípio da "sociabilidade", e, de outro, o reforça, pois, em oposição ao processo de dispersão da população agrícola, gerada pelos 
custos de transporte, esse princípio promove a concentração do comércio e dos serviços em determinados centros. Assim, enquanto a população agrícola se dispersa espacialmente, ocorre a coesão do comércio e dos serviços, gerando, consequentemente, diferenciações entre os centros urbanos, que, por sua vez, são de natureza hierárquica (ROBIC, 1982; CORRÊA, 1986). O princípio da "administração" reforça o "fator econômico", à medida que acrescenta ao processo de coesão do comércio e dos serviços o fator político-administrativo, ampliando, consequentemente, o grau de diferenciação entre os centros e também reforçando, imensamente, a hierarquia entre eles (ROBIC, 1982; CORRÊA, 1986).

Reynaud reconhece, também, que a realidade pode apresentar fatores capazes de gerar distorções quanto à localização dos centros, dentre eles: a presença de cidades industriais, que possuem lógica locacional própria, fundamentada na presença de matéria-prima ou de mercado consumidor; nos custos de transporte, especialmente por meio da presença de vias férreas, que garantem aos centros posição de superioridade; no papel de função militar e de vigilância desempenhada por um ou outro centro; nos efeitos das densidades desiguais de população e também de renda, principalmente junto às capitais; e na questão do crescimento desigual, o que geraria situações de instabilidade (ROBIC, 1982).

Dessa maneira, Reynaud, na explicitação desses três princípios, antecipou cerca de 100 anos o mecanismo de "alcance espacial mínimo" e "alcance espacial máximo" desenvolvido por Christaller (1966), com base nos princípios de "mercado", "transporte" e "administrativo"; assim como a ideia de esquema teórico centrado em uma situação homogênea para a constituição de uma rede hexagonal, haja vista que o hexagrama é a forma ideal para representar espacialmente a rede de localidades centrais.

Nesse contexto de expansão do capitalismo industrial, têm-se, ainda, as contribuições do engenheiro ferroviário León Lalanne, que também conferiu aos centros urbanos franceses padrões hierárquicos distintos (CORREAA, 1986; KANSKY KARL, 1989; DUPUY; CREWS, 1993; PUMAIN, 1994; PUMAIN, 2004). A Revolução industrial exigiu e promoveu a ampliação dos mercados, com o fortalecimento das articulações entre os lugares, particularmente, entre os centros urbanos, possibilitadas pela 
melhoria das comunicações e dos transportes, sobretudo, com os avanços das estradas de ferro.

Lalanne observou que o desenvolvimento ferroviário poderia alterar os padrões locacionais das atividades produtivas e ainda era capaz de modificar a importância absoluta e relativa dos centros urbanos (CORREAA, 1986; KANSKY KARL, 1989). Nesse sentido, a partir do modelo de organização espacial das linhas ferroviárias, Lalanne elaborou, por volta de 1863, um esquema de rede urbana, no qual os centros, notoriamente os entroncamentos ferroviários, estruturavam-se de modo hierárquico. De fato, Lalanne apresentou um dos primeiros ensaios no sentido de "[...] pensar a organização espacial resultante da expansão ferroviária", como aponta Corrêa (1986, p.63), na qual "[...] ele observou relações regulares da rede ferroviária e sugeriu uma relação hierárquica entre a rede e as divisões políticas na França” (KANSKY KARL, 1989, p. 95).

Assim, por meio de um "modelo ideal", semelhante ao de Reynaud, Lalanne orientou um esquema em que a organização espacial dos centros e de suas áreas de influência também adquiria padrões de redes hexagonais, com os núcleos localizados centralmente em relação às respectivas áreas de influência (CORRÊA, 1986; DUPUY; CREWS,1993). Nesse sentido, seu esquema considerava que uma rede ferroviária adensava-se, preferencialmente, à forma triangular. Tais triângulos tenderiam, por sua vez, a agruparem-se de seis em seis em torno de um mesmo ponto central, que se tornaria, simultaneamente, o centro de um hexágono, com seis raios iguais dirigidos, em paralelo, rumo aos ângulos do hexagrama (CORRÊA, 1986). Cumpre registrar que, nesse esquema, o número médio de linhas (o conjunto de linhas) que parte de um ponto central é seis, mas, em centros excepcionalmente importantes, via de regra capitais nacionais, esse número pode ser elevado para 12 linhas. Em regiões onde a rede ferroviária é incompleta, o número de linhas que parte ou chega de um centro não seria mais que três (CORRÊA, 1986).

Dessa forma, cumpre registrar que Lalanne admitia a "lei da equilateralidade", pela qual se percebia um espaçamento regular dos centros ferroviários situados nos ângulos de triângulos equiláteros, o que implicava padrões sistemáticos de distância entre os centros, que se estruturavam de modo hierárquico. 
O capitalismo foi, de fato, o principal impulsionador do processo de hierarquização entre os centros urbanos, pois, à medida que esse sistema produtivo se instalava plenamente, emergia uma rede cada vez mais diferenciada de centros, com processos crescentes de estratificações hierárquicas, haja vista as desigualdades na oferta de produtos industriais e de serviços, bem como no acesso às infraestruturas de comunicação e transporte. De acordo com Corrêa (2001, p. 20), "[...] a rede hierarquizada de localidades centrais constitui-se em uma forma de organização do espaço vinculada ao capitalismo", quer dizer, os centros hierarquizam-se entre si em razão das desigualdades espaciais imposta pelo capitalismo.

A temática da hierarquia urbana foi também estudada nas primeiras décadas do século XX. Dentre os trabalhos, destacam-se os de um grupo de sociólogos rurais estadunidenses, especialmente de Charles. J. Galpin e John H. Kolb (BRUSH, 1953; BERRY; GARRISON, 1958; CORRÊA, 1989; BANTJES, 1997). Esses sociólogos rurais buscavam, a partir de 1915, uma base funcional para a reorganização dos condados de Wisconsin, que resultasse em uma organização fiscal do referido condado, visto que suas intenções eram político-administrativas. Para tanto, partiram da delimitação das áreas de influência dos centros urbanos, com base nos deslocamentos dos agricultores do meio-norte para a aquisição de bens e serviços em pequenos centros. Nessa perspectiva, Charles. J. Galpin, em 1915, propôs a delimitação das áreas funcionais dos centros a partir da determinação das áreas de comércio de cada um, isto é, em razão da distância percorrida pelos lavradores para a obtenção de bens e serviços em um centro (alcance espacial máximo). Isso implicava a determinação da área de mercado de cada um dos centros do condado. Kolb, por sua vez, pesquisou as relações a partir dos serviços prestados por povoados aos residentes de fazendas, em 1923 (BRUSH, 1953; BERRY; GARRISON, 1958; BANTJES, 1997).

A necessidade de compreensão da rede urbana foi também suscitada na esfera do planejamento urbano e regional, especificamente no processo de reconstrução do pós Primeira Guerra Mundial. Nessa perspectiva, colocam-se os estudos de um grupo de planejadores urbanos ingleses, dentre eles, geógrafos e administradores, que, entre os anos de 1918 e 1919, preocuparam-se com a organização espacial da rede de centros ur- 
banos, subsidiando, inclusive, a reestruturação político-administrativa da Inglaterra (FAWCETT, 1932; CORRÊA, 1986). Em 1918, Charles B. Fawcett propôs uma nova divisão territorial para a Inglaterra, pela qual seriam criadas províncias a partir das áreas de influência dos grandes centros urbanos, dentre eles: Londres, Manchester, Birminghan, Bristol, Nottingham e Leeds (FAWCETT, 1932). A ideia de províncias estava, portanto, apoiada na área de influência dos grandes centros ingleses, cuja delimitação estaria amparada no comportamento espacial das pessoas, na acessibilidade aos referidos centros e também na concepção de um limite mínimo de população para que uma província fosse criada (FAWCETT, 1932).

Outros estudos, ainda anteriores à obra de Christaller (1966), foram também realizados, dentre eles, destacam-se as pesquisas dos geógrafos Robert Dickinson, na Inglaterra, Hans Bobek, na Áustria, em 1927, e Vaino Auer, na Finlândia (DICKINSON, 1947; CORRÊA, 1986; HOFMEISTER, 2004). Os estudos de Dickinson privilegiaram, entre os anos de 1929 e 1934, a definição das áreas de influência das metrópoles e outros centros ingleses, alemães e estadunidenses, por meio das funções comerciais e de serviços que esses desempenhavam (DICKINSON, 1947). Tais estudos aproximam-se ainda mais da teoria das localidades centrais, haja vista que consideraram, em uma região homogênea, o jogo particular das condições associadas à densidade da população, capacidade funcional, competição entre os centros, dinâmica regional, distância entre os centros, zonas/ esferas de influência, acessibilidade/facilidade de circulação, dentre outras, próprias de um esquema hierárquico, no qual os centros com população e centralidade maiores tinham os centros menores como tributários, em sua hinterlândia (DICKINSON, 1947).

\section{Considerações finais}

Os estudiosos aqui mencionados foram capazes de perceber, a partir do século XVIII, a importância da rede de centros urbanos e a complexificação desta fundamentada nas transformações do capitalismo, apesar do contexto positivista. Assim, esses estudiosos tiveram a habilidade de notar 
o momento em que a realidade urbana mostrou-se problematizada por meio da existência de diferenças entre os núcleos de povoamento, inclusive, diferenças de caráter hierárquico. Desse modo, há que se ressaltar a historicidade de tal processo, sendo que, a esse respeito, Corrêa (2001, p. 20) afirma que "[...] a rede hierarquizada de localidades centrais constitui-se em uma forma de organização do espaço vinculada ao capitalismo, sendo, portanto, de natureza histórica". Destarte, cabe a esses estudiosos o mérito de tornar inteligível a realidade no momento de sua gênese, bem como no percurso das primeiras transformações.

Em virtude de tal situação, esses precursores desenvolveram ideias autônomas e independentes de qualquer outra teoria, sendo, portanto, pioneiros nos estudos sobre o significado da diferenciação de natureza hierárquica entre os centros urbanos. Tais estudos foram, posteriormente, sistematizados e adensados por Christaller (1966), cerca de 180 anos após os primeiros esforços de compreensão da natureza hierárquica das relações interurbanas. De modo semelhante, os antecessores de Christaller (1966) perceberam o processo de diferenciação entre os centros e apontaram estratificações de caráter hierárquico na rede urbana, colocando em destaque os mecanismos econômicos e espaciais capazes de gerar essas relações hierárquicas. Tais mecanismos foram aprofundados por Christaller (1966), excepcionalmente no que diz respeito ao alcance espacial (mínimo e máximo) e ao padrão hexagonal da rede de localidades centrais, que definiria padronizações sistemáticas de distância entre os centros de um dado segmento de rede.

Cumpre registrar que os pioneiros dos estudos sobre rede urbana não se dedicavam à geração de conhecimentos acadêmicos. Na verdade, eram "homens de negócios" ou "homens da administração", que, em razão de suas práticas econômicas e administrativas, levantaram questionamentos sobre a organização espacial dos centros urbanos. Tais questionamentos foram formulados também por Christaller (1966), que, já na introdução de seu trabalho, questionava a possibilidade de haver leis que determinassem o tamanho, o número e a distribuição dos centros urbanos no território.

A descoberta ou redescoberta dos precursores de Christaller (1966) propicia o reconhecimento à contribuição desses estudiosos. O resgate da produção intelectual desses antecessores permite a valorização do esforço 
empreendido na construção pioneira do conhecimento e auxilia a ver os fatos do presente, assim como revela que, em determinados momentos, fazem-se necessárias a sistematização e a ordenação de conhecimentos dispersos. No caso específico, cumpre registrar que a teoria elaborada por Christaller (1966) encontra-se apoiada nas ideias originais de vários estudos empíricos, que arriscaram definir a hierarquia urbana e as tipologias que classificassem os centros, ainda no século XVIII, quando uma rede de centros urbanos começava a emergir de uma economia de mercado, que, gradativamente, interligava e diferençava de forma desigual e estratificada os núcleos urbanos, as regiões e os próprios países.

A importância desse debate está vinculada aos rumos que as discussões sobre rede urbana e hierarquia tomam no presente, especialmente, por conterem e estarem contidas num movimento mais amplo de urbanização da sociedade, explicitado em sua dimensão espacial. A compreensão dos contextos histórico-geográficos apresenta-se paralela à compreensão dos próprios conceitos, no sentido de articular o passado ao presente. Rede urbana e hierarquia estão no debate atual, pois envolvem relações entre questões econômicas, políticas e sociais e suas relações globais e sistêmicas, notadamente, determinadas por um mundo em constante mutação, que representa um desafio permanente.

\section{Referências}

BANTJES, Rod. Benthamism in the countryside: the architecture of rural space, 1900-1930. Journal of Historical Sociology, v. 10, n.3, p. 249-269, sep.1997. BERRY, Brian J. L.; GARRISON, William L. The functional bases of the central place hierarchy. Economic Geography, v. 34, n.2, p. 145-154, apr.1958.

BRUSH, John E. The hierarchy of central places in Southwestern Wisconsin. Geographical Review, v. 43, n.3, p. 380-402, jul.1953.

CHRISTALLER, Walter. Central places in Southern Germany. Prentice-Hall/ Englewood Cliffs, 1966. 230p.

CORRÊA, Roberto Lobato. Estudos sobre rede urbana. Rio de Janeiro: Bertrand Brasil. 2006. 330p. 
CORRÊA. Repensando a teoria das localidades centrais. In: Trajetórias geográficas. Rio de Janeiro: Bertrand Brasil, 2001. p.15-40.

. A rede urbana. São Paulo: Ática, 1989. 96p.

. As redes de localidades centrais nos países subdesenvolvidos. Revista Brasileira de Geografia, Rio de Janeiro, ano 50, n.1, p.61-83, jan./mar.1988.

. O enfoque locacional na Geografia. Revista Terra Livre, Rio de Janeiro, ano 1, n.1, p. 62-66, 1986.

DICKINSON, Robert E. City region and regionalism. A geographical contribution to human ecology. London, 1947. 327p.

DUPUY, Gabriel; CREWS, Judith. Networks. Flux, n.11, p. 42-47, 1993.

FAWCETT, C. B. Distribution of the urban population in Great Britain, 1931.

The Geographical Journal, London, v. 79, n. 2, p. 100-113, feb.1932.

HOFMEISTER, Burkhard. The study of urban form in Germany. Urban Morphology, v. 8, n. 1, p. 3-12, 2004.

KANSKY KARL, Danscoine Pascal. Measures of network structure. Flux, numéro spécial, p.89-121, 1989.

PONSARD, Claude. Histoire des théories economiques spatiales. Paris: Armand Colin, 1958. 202p.

PUMAIN, Denise. L'invention permanente: la hiérarchie urbaine. In: L'invention dans les sciences humaines. Genève: Editions Labor et Fildes, 2004. p. 66-86.

PUMAIN, Denise. La modelisation des reseaux urbains. Relatório PIR Cidades, 1994.

ROBIC, Marie-Claire. Cent ans avant Christaller... une théorie des lieux centraux. L’Espace Géographique, Paris, n.1, p. 5-12, 1982.

SANTOS, Milton. Metamorfoses do espaço habitado. São Paulo: Hucitec, 1994. 124p.

O espaço dividido: os dois circuitos da economia urbana dos países subdesenvolvidos. Rio de Janeiro: Francisco Alves, 1979. 345p.

SPOSITO, Maria Encarnação B. A produção do espaço urbano: escalas, diferenças e desigualdades socioespaciais. In: CARLOS, Ana Fani A.; SOUZA, Marcelo L. de; SPOSITO, Maria Encarnação B. A produção do espaço urbano: agentes e processos, escalas e desafios. (Org.). São Paulo: Contexto, 2011. p. $123-145$. 
VELTZ, Pierre. Des lieux et des liens: politiques du territoire à l'heure de la mondialisation. Paris: Éditions de l'Aube, 2002. 160p.

Recebido em: 05/03/2012

Aceito em: 16/05/2012 
